\title{
Identidade Chanel: uma análise semiótica das campanhas publicitárias impressas do perfume №5
}

Chanel identity: a semiotic analysis of the publicity campaigns printed of the perfume $N$ 으

SILVA, Bruna; Graduanda; Instituto Federal de Ciência e Tecnologia de Santa Catarina brunaramos.s.br@gmail.com

FERREIRA, Mariana Caroline; Graduanda; Instituto Federal de Ciência e Tecnologia de Santa Catarina

ferreiramarianacaroline@gmail.com

ORTIGA, Priscila; Mestrando; Instituto Federal de Ciência e Tecnologia de Santa Catarina priortiga@gmail.com

\section{Resumo}

O presente artigo consiste numa análise semiótica das campanhas publicitárias da marca Chanel, como forma de identificar os signos que colaboram para a atemporalidade e legitimidade da Chanel no mercado da moda mundial. A título de recorte, foram escolhidas as campanhas impressas do perfume Chanel №5 para a execução dessas análises, com ênfase nas protagonistas representadas nestas. No universo da moda, a marca Chanel é considerada um ícone, o sonho de consumo de muitas mulheres. Já na semiótica, é uma importante referência de estudo, devido à permanência de sua imagem no cenário da moda mundial. Portanto, como resultado desta análise, foi possível evidenciar os meios utilizados pela marca para tal sucesso, bem como o papel que as protagonistas exercem no processo de comunicação e sedução com o público consumidor. Para tal, seguiu-se o método de pesquisa qualitativa com levantamento bibliográfico e iconográfico seguidos por uma análise diacrônica e semiótica.

Palavras Chave: Chanel; Publicidade; Protagonistas.

\section{Abstract}

This article is a semiotic analysis of the advertising campaigns of the Chanel brand as a way of identifying the signs that contribute to the timelessness and legitimacy of Chanel in the world fashion market. As a clipping, the printed campaigns of the Chanel No. 5 perfume were chosen for the execution of these analyzes, with emphasis on the protagonists represented in these. In the fashion world, the Chanel brand is considered an icon, the consuming dream of many women. On another hand in the semiotics, it is an important reference of study, due to the permanence of its image in the scene of the world fashion. Therefore, as a result of this analysis, it was possible to highlight the means used by the brand for such success, as well as the role that the protagonists 
play in the process of communication and seduction with the consumer public. For that, the method of qualitative research followed with a bibliographical and iconographic survey followed by a diachronic and semiotic analysis

Keywords: Chanel; Publicity; Protagonists

\section{Introdução}

A marca Chanel é um grande ícone do universo da moda, que ficou conhecida por sua elegância simples, e tornou-se um sinônimo de luxo e sofisticação. O grande sucesso da marca, deve-se também à criação de seu perfume, o №5, que é considerado o perfume mais vendido do mundo (COSGRAVE, 2012; ROUX, 2005).

Desde seu surgimento em 1921, o frasco original do perfume №5 sofreu poucas e discretas modificações, atribuindo a este um caráter atemporal, já que, mesmo com as modificações no tempo e na sociedade, conseguiu manter a essência de sua imagem intacta. 0 mesmo aplica-se à própria marca, que permanece até os dias atuais com os mesmos predicativos e o mesmo público consumidor que possuía no início de sua criação (COSGRAVE, 2012; MAZZEO, 2011; SITE CHANEL).

Portanto, o objetivo principal desta pesquisa pautou-se na necessidade de compreender e evidenciar como a marca Chanel adapta-se às mudanças temporais que ocorrem constantemente na sociedade sem alterar sua imagem, e quais os meios que ela utiliza para alcançar sempre o mesmo público consumidor.

Para isso, buscou-se analisar as campanhas publicitárias impressas do grande ícone da marca, o perfume Chanel №5, já que segundo Lipovetsky (2009) é através da publicidade que uma marca persuade e atrai seu público consumidor, evidenciando seu valor simbólico por meio dos signos semióticos (KNOLL, 2012, SCOZ; MOTTA, 2016).

Para tal, o uso da semiótica como instrumento de análise torna-se indispensável, já que esta se trata de uma ciência que estuda os signos e seus processos de significação (SANTAELLA, 1983). Sendo assim, para compreender como a significação da imagem nas campanhas publicitárias acontece, é necessário analisá-las, traduzindo e decodificando os signos presentes e apresentando seus possíveis significados (RAMALHO,2004; NIEMEYER,2007).

\section{A marca Chanel e a mulher Chanel}

A marca Chanel surgiu em 1910 idealizada por Gabrielle Chanel, que revolucionou o mundo da moda feminina ao propor um vestuário elegante e minimalista, que divergia ao estilo vigente na década, que era caracterizado por uma indumentária rígida, com espartilhos que serviam para dar ênfase à silhueta feminina (COSGRAVE, 2012; CASTILLO, VILLAÇA et al. 2006).

Com essa quebra de paradigmas, a marca Chanel passou a representar uma conquista pela liberdade individual feminina, incentivando à busca pela liberdade e pelo conforto, sem abrir mão da elegância e do luxo (ROUX, 2005; COSGRAVE, 2012). A partir disso, estabeleceu-se uma identidade de marca e um padrão de público alvo, e a Chanel passou a ser símbolo de mulher elegante, sofisticada que busca pela sua liberdade (ROUX, 2005. MIRANDA, 2008). 
Contudo, sua influência não se limitou apenas ao guarda-roupa, em 1921 Coco Chanel criou seu primeiro perfume o Chanel №5, com a ajuda do perfumista Ernest Beaux, que lhe apresentou para a escolha da fragrância, duas séries de amostras numeradas de 1 a 5 e de 20 a 24. Dentre essas fragrâncias, a escolhida foi a amostra no5 que deu nome ao perfume (CASTILLO; VILLAÇA et al. 2006). Gabrielle Chanel queria que seu perfume fosse uma verdadeira criação, um paradoxo, uma essência intensa que colasse à pele e fosse tão versátil quanto suas roupas (COSGRAVE, 2012). Com isso, o №5 tornou-se um ícone, um símbolo de luxo e desejo, sendo desde sua criação, até hoje, o perfume mais vendido no mundo (NORA; SANTOS, 2015; MAZZEO,2011).

Além disso o №5 foi um dos primeiros produtos Chanel a ter uma campanha publicitária, em 1921, na qual, representava não somente o perfume, mas uma mulher elegante e sofisticada, a mulher Chanel (ver figura 1). Foi através dele que a marca pôde legitimar-se e estabelecer-se no mercado (COSGRAVE, 2012). Isso, devido à popularização dos perfumes nessa época, que por serem considerados um luxo acessível às massas, levou nomes da moda ao prestígio (BRAGA, 2006).

Figura 1: Campanha de 1921 do perfume Chanel №5

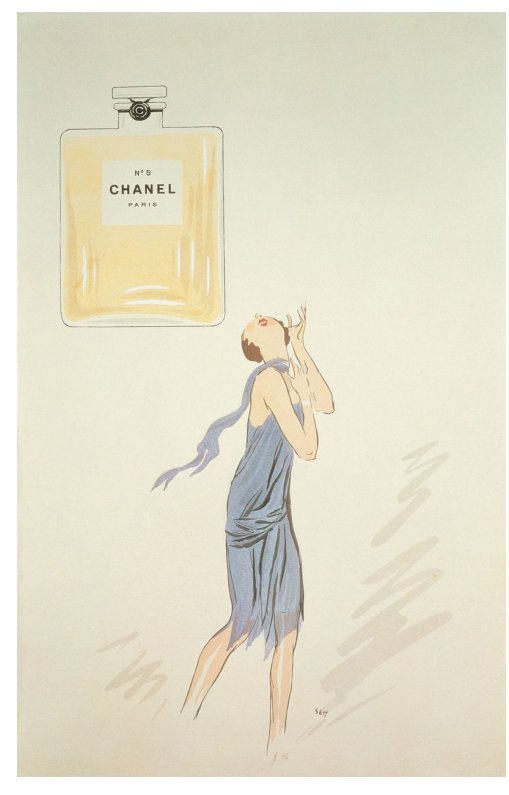

Fonte: chanel.com/pt_BR/

Ademais, durante a Segunda Guerra Mundial ${ }^{1}$ não houveram campanhas publicitárias do perfume. E antes mesmo de lançar sua primeira campanha pós Guerra, a Chanel conseguiu retornar ao sucesso novamente, e desta vez com a ajuda da mídia, após Marilyn Monroe declarar em entrevistas que utilizava o perfume №5. Diante disso, a marca pôde legitimar-se de maneira permanente no mercado, associando-se mais uma vez à imagem de mulher elegante e sofisticada (CHANEL, 2018 ).

\footnotetext{
1 As campanhas foram retiradas do site oficial da Chanel. Ao observar a cronologia das campanhas, percebeu-se que na década de 1940 não há publicada nenhuma campanha do perfume. Portanto, supõe-se que isso se deve ao acontecimento da Segunda Guerra Mundial nesta mesma década.
} 
Já que, como dito acima, tal legitimidade deve-se à associação da marca com a imagem de um perfil feminino, compreende-se a necessidade de um meio que estude, analise e compreenda tais representações de imagem, e assim, a semiótica.

\section{Semiótica}

A semiótica é a ciência que estuda os signos e seus processos de significação (semiose). Neste viés, a semiologia proposta por Peirce busca investigar e analisar todas as formas de linguagem, verbal ou não-verbal, para compreender e classificar as formas como estas constituem-se através dos significados ou signos (SANTAELLA,1983). Sendo assim, para Peirce, um signo ou representamên é tudo aquilo que significa algo para alguém, necessitando então da interação entre um objeto e um interpretante (Peirce, 1972).

Para categorizar esse processo de significação, Peirce desenvolveu a fenomenologia, que é composta por três princípios universais, que serão descritos abaixo segundo Nöth (2003) ;Santaella (1983):

Primeiridade: é a primeira impressão do objeto como tal , sem analisá-lo ou relacioná-lo a outros elementos ou fenômenos presentes.

Secundidade: é o elemento da experiência, e inicia-se quando o primeiro fenômeno é relacionado a um segundo fenômeno, comparando esse a um evento passado.

Terceiridade: é a categoria da síntese, da comunicação e da interpretação das relações, é onde inicia-se o pensamento através de signos. É onde são interpretadas, analisadas e organizadas as informações obtidas nas categorias anteriores.

Dentro dessas categorias estão os signos, que podem ser classificados de acordo com a segunda Tricotomia, que é considerada "a categoria mais importante dos signos" (PEIRCE, 1977 apud NÖTH, 2003):

Abaixo as definições descritas por Santaella (1983).

Ícone: É um representamêm (signo), a impressão projetada na mente para representar algo. 0 ícone é apenas a representação imagética de algo, sem ser necessariamente a coisa em si .

Índice:é uma relação que indica uma conexão entre o objeto e outra coisa, sendo assim, o índice só funciona através de uma "mente interpretadora", para estabelecer essa conexão.

Símbolo: representa algo através de uma lei por convenção ou pacto coletivo, trazendo em si ícones e índices.

Figura 2: tabela processo de significação

\begin{tabular}{|c|l|l|l|}
\hline Fenomenologia & Segunda tricotomia & Signo & Características \\
\hline Primeiridade & Ícone & Perfume Chanel №5 & $\begin{array}{r}\text { Primeira percepção do perfume, } \\
\text { primeira imagem que vem à mente seja } \\
\text { ela qual for. }\end{array}$ \\
\hline & & & Através da experiência sabe-se que um \\
\hline
\end{tabular}



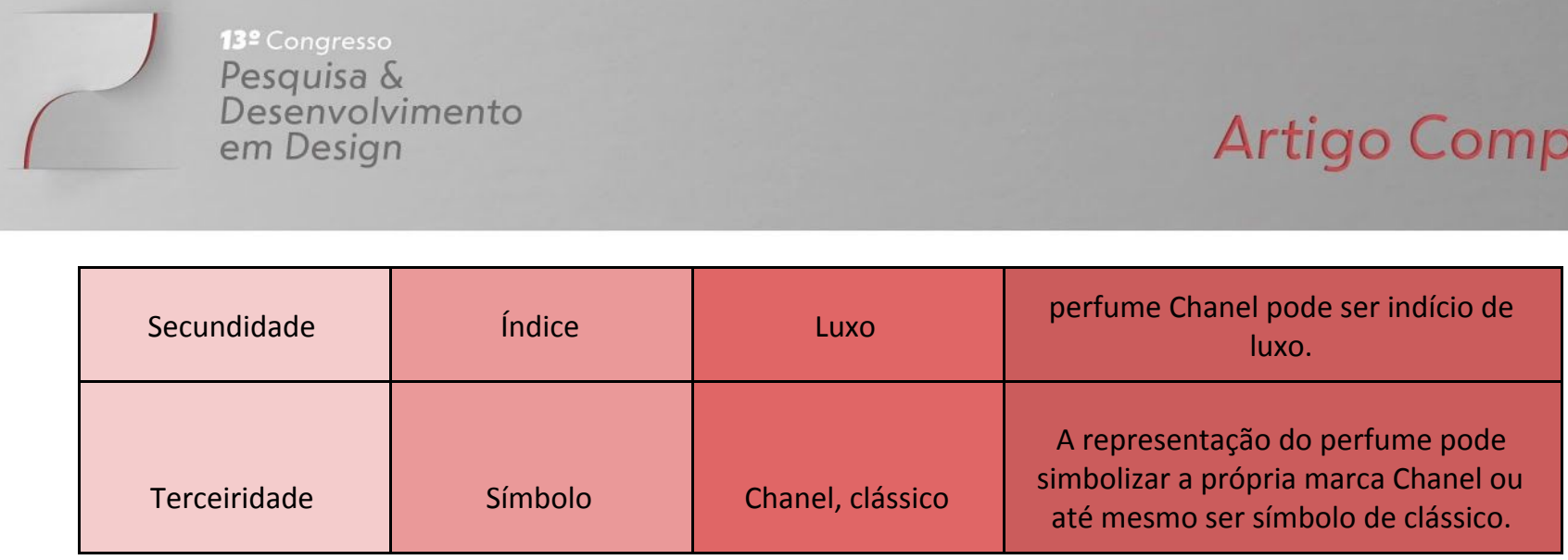

Fonte: Adaptada de Peirce (1972).

No quadro acima são exemplificadas as etapas que ocorrem dentro do processo de significação. Passando pela primeiridade, secundidade e terceiridade, respectivamente. Neste último, ocorre a segunda tricotomia, onde a percepção obtida passa a ser categorizada em signos, sejam eles ícones, índices ou símbolos. Em suas definições, primeiridade-ícone, secundidade-índice e terceiridade-símbolo podem ser confundidas, já que estas se assemelham. Contudo, é importante ressaltar que, a fenomenologia são as etapas do processo de significação, enquanto a segunda tricotomia corresponde aos signos que são gerados a partir destas etapas.

Estas definições são de grande importância para que sejam realizadas as análises semióticas segundo a teoria peirceana.

\section{Análise semiótica no design e na publicidade}

É por meio da realização de análises semióticas, considerando os preceitos explicados acima, que é possível compreender como uma marca comunica seu produto. Para tal, é necessário levar em consideração diversos elementos objetivos e subjetivos, como cores, texturas, dimensões, percepção, etc. Estes fatores são de caráter decisivo para dar significado à determinado produto e para alcançar seus futuros usuários (NIEMEYER, 2007). Portanto, são os signos presentes em determinado produto que são responsáveis por estabelecer e consolidar seu valor perante os consumidores (SCOZ; MOTTA, 2016; MIRANDA, 2008).

Para Belchior (2014), o designer passa a ser então, um grande manipulador de signos, pois através da semiose consegue construir e atribuir conceitos aos objetos de design. FORTY (2007, p.20) corrobora essa informação ao dizer que "o design altera o modo como as pessoas vêem as mercadorias".

Ainda assim, o design pode e deve contar com o auxílio de outros meios para alcançar uma comunicação mais efetiva de seu produto, agregando mais visibilidade para seu significado, como o marketing e a publicidade, por exemplo (DENIS 1998 apud BELCHIOR 2014). Krucken (2008) concorda com essa afirmação ao dizer que é necessário conectar conhecimentos e ter uma "visão periférica" dentro de um projeto para que este obtenha sucesso. Portanto, é possível fazer uma relação entre o que Niemeyer (2007) explica sobre análise semiótica de produto e análise semiótica de campanhas publicitárias, já que ambos pertencem à uma marca e possuem como objetivo: vender e lucrar, e para tal fazem uso dos signos (FORTY, 2007).

\subsection{A importância da publicidade para a manutenção da marca}

A publicidade vem invadindo o cotidiano das pessoas constantemente, através de meios de comunicação como televisão, filmes, rádio, revistas etc, trazendo consigo uma linguagem repleta de enunciados persuasivos, a fim de atrair o consumidor (LIPOVETSKY, 2009). Knoll (2012) 
aponta que a publicidade atua no polo de produção e de consumo, agregando significados às marcas/produtos que estimulam o público à consumí-los. Para CARVALHAL $(2016$, p.93) este é o meio pelo qual a marca pode se diferenciar das demais e transmitir seus sentimentos e emoções, características estas, que segundo o autor, tornam a marca um "organismo vivo".

Existem demandas psicossociais em jogo no ato de consumir, que envolvem sentimentos como auto estima, status, evolução pessoal e conquista (MASLOW, 1984 apud KNOLL, 2012). É dentro deste viés que a publicidade atua, produzindo elementos de sedução e fantasia como truques para atrair a atenção do consumidor (LIPOVETSKY, 2009). Para que isso ocorra, são representados nas campanhas, papéis sociais que acredita-se serem os mais comuns dentro de uma sociedade, para que assim o consumidor auto-identifique-se e receba a mensagem que a campanha deseja passar (BAGGIO, 2016).

Dessa forma, é através desses elementos e estratégias, que de acordo com os princípios da semiótica podem ser chamados de signos, que as marcas constroem sua identidade, alcançam seu público e se mantém no mercado (BELCHIOR, 2014). Portanto, a identidade que a marca assume, e os sentimentos e emoções que ela proporciona ao público é o que atrai os consumidores, que por sua vez procuram consumir a marca com a qual se identificam. Miranda (2008) corrobora, ao dizer que as mulheres consomem a imagem (marca) que gostariam de ver de si mesmas.

Por este motivo, muitas marcas, como a própria Chanel, utilizam da imagem de celebridades reconhecidas como meio de formar a personalidade e significados que serão atribuídos à marca (MIRANDA, 2008). De acordo com Miranda (2008), esse tipo de estratégia, no qual se atribui personalidade à marca, serve para diferenciar os produtos de uma mesma categoria de marcas diferentes. Roux (2005) consegue resumir todo esse processo de diferenciação em uma só palavra: legitimidade, que ele define como efeito de consagrar e atribuir qualidade, criando uma imagem criativa e original aliada à exclusividade, tornando a marca permanente e contínua.

A marca Chanel como uma marca clássica e de identidade singular, se inscreve na moda de forma permanente, e compartilha seus significados e valores através da representação das protagonistas nas campanhas, que representam uma mulher elegante, sofisticada e que busca sua liberdade (ROUX, 2005. MIRANDA, 2008). Dessa forma, ao consumir um produto Chanel, o usuário espera adquirir a sofisticação transmitida pela marca. Como exemplifica:

"Se consumirmos por desejo e necessidade, significa que não possuímos produtos, mas o textos, os discursos, as narrativas que estão impressas neles, na imagem que foi elaborada" (MIRANDA, 2008. p.34). Ou seja, as estratégias que permeiam os valores das marcas e dos produtos são o real objeto de consumo, que atraem e seduzem o consumidor. Para CARVALHAL (2016, p.93) uma marca é como um "organismo vivo" que pode transmitir sentimentos e emoções.

No caso da união da moda e da publicidade, o consumidor é atraído com a promessa de consumir todas as qualidades intrínsecas ao espírito transmitido pela marca, sejam eles, beleza, luxo, sofisticação, delicadeza, liberdade, etc. Miranda (2008) ainda faz uma diferenciação entre marca funcional e simbólica, sendo a funcional a que satisfaz aspectos práticos, e a simbólica a que satisfaz necessidades simbólicas como identidade e prestígio. 


\section{Procedimentos metodológicos}

O presente artigo é fruto de uma pesquisa realizada com a tutoria do PET (Programa de Educação Tutorial) do Curso Superior de Tecnologia em Design de Produto do Instituto Federal de Santa Catarina (IFSC).

Para o desenvolvimento das análises aqui apresentadas, seguiu-se o método de pesquisa qualitativa, que consiste no reconhecimento e na análise de diferentes perspectivas, descobrindo novas teorias utilizando como referência o objeto que está sendo estudado (FLICK, 2009). A pesquisa iniciou-se com um levantamento bibliográfico da marca Chanel e do perfume №5 e das demais pesquisas ligadas aos principais elementos do projeto, como semiótica e publicidade. Tudo com o intuito de levantar informações relevantes necessárias para a elaboração da análise semiótica que será realizada.

Para isso, foi realizada uma pesquisa documental iconográfica no site oficial da marca Chanel, no qual foram selecionadas as campanhas publicitárias do perfume №5, por se tratar do ícone da marca. A título de recorte, foram selecionadas seis campanhas, dando preferência às que representassem mudanças mais marcantes na forma de representação da figura feminina em diferentes décadas. Para demonstrar essas mudanças foram selecionadas as campanhas dos anos de 1937, 1957, 1975, 2000, 2009 e 2014. Em seguida, realizou-se uma análise diacrônica, a fim de demonstrar a evolução e as mudanças sofridas pela representação da mulher Chanel ao longo da décadas, levando em consideração o papel social da mulher na sociedade em cada momento desta linha do tempo (BONSIEPE, 1984).

Figura 3: Linha do tempo das campanhas publicitárias impressas do perfume Chanel №5

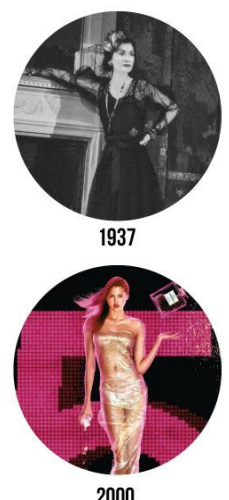

Fonte: Elaborado de chanel.com/pt_BR (2017)

Por fim, as campanhas impressas do perfume №5 foram analisadas segundo a semiologia peirceana, utilizando seus preceitos de primeiridade, secundidade e terceiridade, explorando os modos como os signos são utilizados através das protagonistas presentes nas campanhas publicitárias como modo de atrair o público consumidor e legitimar a marca Chanel.

\section{Resultados e discussões}

A marca Chanel é, como dito anteriormente, uma grande referência para o mundo da moda, pois criou um novo padrão na moda, a sofisticação com conforto e simplicidade. Para ela, o 
conforto e a simplicidade eram requisitos essenciais: "Se o luxo não for confortável, não é luxo" (CHANEL apud COSGRAVE, 2012).

Além disso, a marca também trouxe consigo uma nova proposta de comportamento feminino, representando uma mulher moderna independente. Desta forma, a marca Chanel legitimou-se no mercado e consagrou sua imagem de maneira atemporal, influenciando e conquistando sempre o mesmo público, sem modificar sua essência e a de seus produtos.

Sua imagem é fortemente evidenciada em suas campanhas publicitárias ao longo das décadas, adequando-se às mudanças de contextos sociais, principalmente às mudanças ocorridas no papel social da mulher, mas sempre enaltecendo a figura de uma mulher moderna, confiante e singular. É neste viés que a análise semiótica se encaixa, como um meio de compreender as representações presentes nas campanhas publicitárias.

Abaixo, a análise realizada com base nos preceitos da semiótica peirceana, considerando a fenomenologia e a segunda tricotomia, que foram explicadas anteriormente.

1 - A primeira campanha analisada foi a do ano de 1937, protagonizada pela própria criadora da marca Gabrielle Chanel, a primeira campanha do perfume que obteve presença de protagonista por meio da fotografia:

Figura 4: campanha de 1937

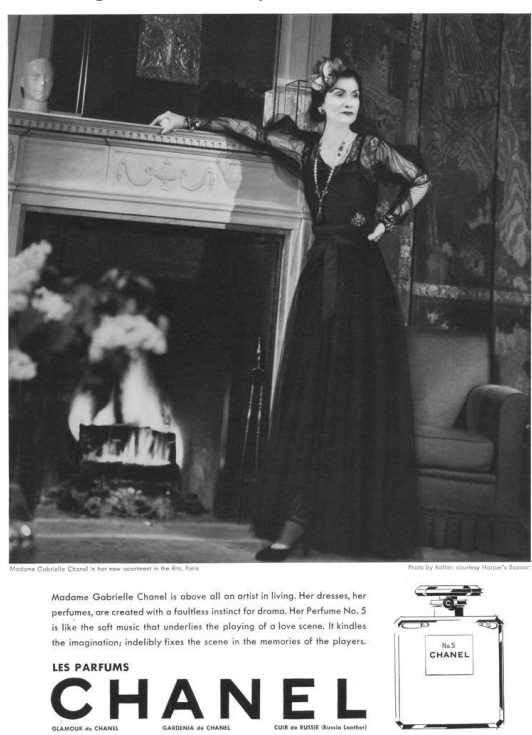

Fonte: chanel.com/pt_BR (2017)

Primeiridade: Gabrielle apresenta-se disposta na imagem como figura central em maior destaque, seguido do fundo que possivelmente é o interior de sua casa onde os elementos como a lareira à esquerda e poltrona à direita ficam em segundo plano. Abaixo encontra-se o texto descritivo acerca do perfume e da mulher chanel ,no canto direito a imagem do perfume e ao centro "Les Parfums Chanel" (os perfumes Chanel) e o frasco do perfume Chanel №5.

Secundidade: Em trajes elegantes Gabrielle apresenta-se em posição de destaque, ao fundo da campanha percebe-se elementos remetentes a casa de Gabrielle ou possivelmente ao Ritz local que frequentava, sua decoração e o mobiliário no estilo "barroco", como a poltrona à direita e a lareira à esquerda, na qual, Gabrielle está apoiada para a pose. O vestido usado por chanel é 
longo uma característica da década de 30, devido a crise de 1929 e a segunda guerra mundial teve reflexo na moda com o retorno do luxo e sofisticação (BRAGA, 2004. CALLY; BLACKMAN, 2004).

Terceiridade: o perfume está abaixo da fotografia o que demonstra que Gabrielle é o grande enfoque da campanha, ou seja, Gabrielle simboliza o próprio perfume e isso é percebido na descrição presente no rodapé da campanha com a seguinte frase: "Madame Gabrielle Chanel is above all an artist in living. Her dress, her perfumes are created with a faultless instinct for drama. Her perfume № 5 is like the soft music that underlies the playing of love scene. It kindles the imagination, indelibly fixes the scene in the memories of the players". que traduzido para o português significa: "Madame Gabrielle Chanel é acima de tudo uma artista em viver. Seu vestido, seus perfumes são criados com um instinto impecável para o drama. O perfume № 5 é como a música suave que está subjacente ao jogo da cena do amor. Ele acende a imaginação, fixa indevidamente a cena nas memórias dos jogadores". O texto reverencia a mulher Chanel e a define como um grande ícone que revela sua melhor essência, por meio dos produtos da marca incluindo o perfume, inspirando as mulheres a serem elegantes e sedutoras como ela ao borrifar o Chanel №5.

2 - A segunda campanha analisada foi a do ano de 1957, protagonizada pela atriz Suzy Parker, que era considerada um dos ícones femininos da década de 50:

Figura 5: Campanha de 1957

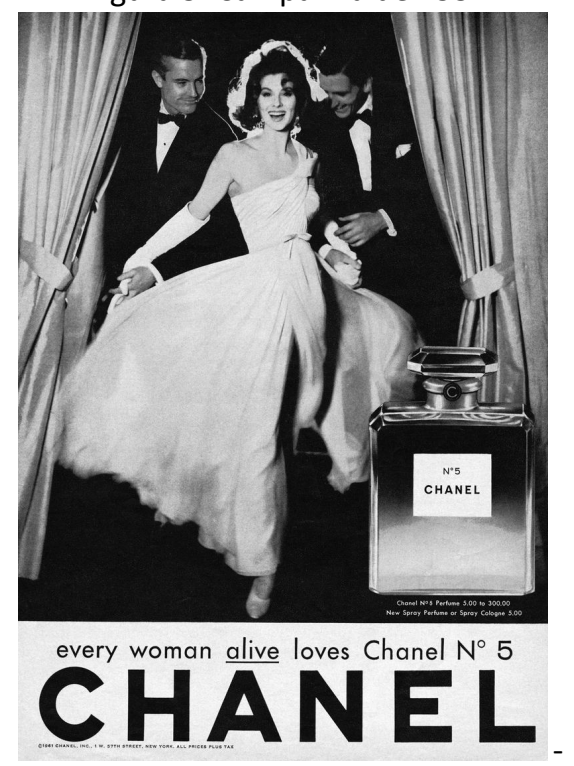

Fonte: chanel.com/pt_BR (2017)

Primeiridade: Lançada nas cores preto e branco, a campanha se passa num cenário que remete a um palco luxuoso, no qual a protagonizada é uma mulher alegre que traja um vestido esvoaçante de gala, e que aparentemente está sendo cortejada por dois homens. Um pouco a frente desta cena, no canto direito, o frasco do perfume №5 e logo abaixo a frase "every woman alive loves Chanel №5", que traduzido para o português quer dizer: "toda mulher viva ama Chanel №5". Ainda abaixo dessa frase, o nome Chanel recebe destaque, estendendo-se por toda extremidade inferior da campanha. 
Secundidade: A mulher representada na campanha faz referência à outro ícone feminino da década de 50, Marilyn Monroe, representando o contexto da moda na década de 50, no qual a mulher usava saias rodadas, espartilhos, sapatos de saltos altos e luvas (BRAGA, 2004). Além disso, a campanha firma um paradoxo com o papel social da mulher que no período de pós Guerra era definido por: "Ser mãe, esposa e dona de casa"(BASSANEZI, 2006, p.609) ao representar uma mulher autoconfiante e independente, que assume a frente da campanha passando a imagem masculina para trás. A cor preto e branco, exaltam as principais cores da paleta da Chanel, que para Gabrielle, eram cores que se completavam.

Terceiridade: A figura feminina feminina é o grande ícone representado na campanha, que passa a imagem de mulher confiante, independente e alegre, além de fazer referência à imagem de Marilyn Monroe. Todavia, é também um índice de tempo e contexto social, que indica se tratar de uma campanha da década de 1950. O perfume e a escrita "CHANEL" são índices que indicam ao leitor o propósito da campanha. A imagem do cenário e os trajes dos protagonistas são símbolos de luxo e sofistição e a palavra "alive" (viva) presente na frase: "toda mulher viva ama Chanel №5", simboliza a alegria, autoconfiança e liberdade que representam a mulher chanel. O preto e o branco simbolizam a paleta da Chanel.

3 - A terceira campanha analisada foi a do ano de 1975, protagonizada pela atriz Catherine Deneuve, foi produzida exclusivamente para ser exibida nos Estados Unidos:

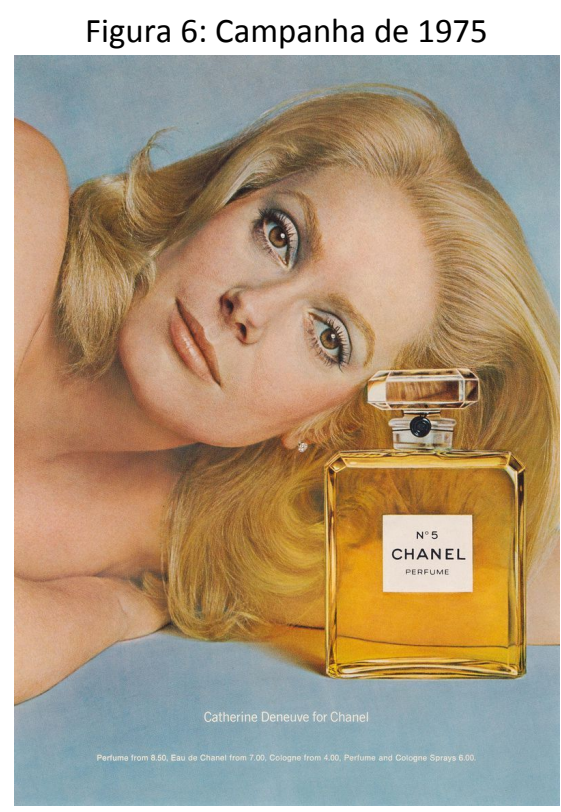

Fonte: chanel.com/pt_BR (2017)

Primeiridade: A campanha do ano de 1975 possui cores em tons pastéis, tanto na leveza do fundo azul quanto na simplicidade da protagonista. A protagonista, que parece estar nua, é representada por uma mulher que transmite naturalidade e leveza. O perfume, novamente à frente da campanha e no canto inferior direito, recebe destaque na campanha, com um amarelo vibrante que contrasta com o fundo pastel. Logo abaixo, a frase "Catherine Deneuve for Chanel." que traduz-se Catherine Deneuve para Chanel. 
Secundidade: A mulher representada na campanha faz referência à simplicidade e a naturalidade que se tornaram moda na década de 70 (LAVER, 1989; POLLINI, 2007). Além disso, o fato dela aparentar estar nua, também representa os protestos ocorridos em prol dos direitos femininos. Além de exaltar a cor da pele da protagonista, o bege, uma das cores da paleta de Chanel, que representam naturalidade e elegância. Entretanto, a protagonista está utilizando um brinco de pérola, referência da marca Chanel, uma contradição ao contexto social, já que nessa década o foco estava nos acessórios baratos, o que não impedia Gabrielle de transportar elegância à um acessório "barato".

Terceiridade: A protagonista é um ícone de feminilidade, que representa a simplicidade que a marca sempre defendeu. Além disso, é também um índice de tempo, que indica as características da década de 70. O perfume também é um índice que indica o objetivo da campanha. $O$ azul pastel e a cor bege exaltada na pele da protagonista, são um símbolo de naturalidade e espiritualidade, enquanto que o brinco de pérola simboliza a singularidade e elegância da Chanel.

4 - A quarta campanha analisada foi a do ano de 2000, protagonizada pela atriz Estella Warren conhecida por participar do elenco do filme Planeta dos Macacos:

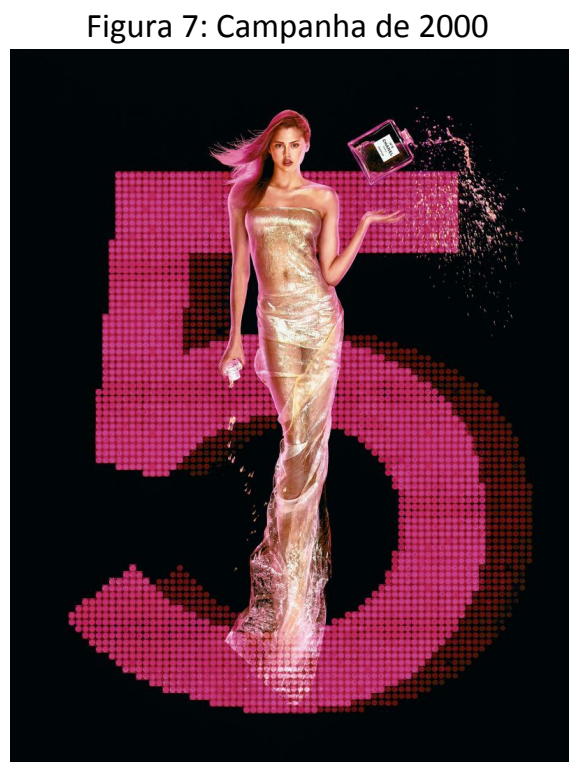

Fonte: chanel.com/pt_BR (2017)

Primeiridade: A campanha do ano 2000 possui cores fortes e vibrantes. Nela, a protagonista representada é uma mulher jovem e sedutora que está envolta por um plástico transparente que remete a um vestido. Logo atrás, o número 5 destacado em tom rosa vibrante, que apesar de estar em segundo plano, ocupa grande parte da campanha. Há dois frascos do Perfume Chanel №5 representados na campanhas, um está flutuando acima da mão esquerda da protagonista, e o outro está em sua mão direita. Ambos estão tendo seu conteúdo despejado no chão. Por fim, o fundo preto que dá destaque aos demais elementos citados anteriormente.

Secundidade: Apesar de ter sido lançada no ano de 2000, a campanha traz consigo características muito marcantes da década de 90, onde a preocupação estética passou a ser supervalorizada com a popularização das academias e a democratização das cirurgias plásticas (BRAGA, 2004; ROCHA, 2011). Por este motivo, a protagonista trás em sua representação uma quebra do padrão das 
campanhas do perfume que foram analisadas até então, onde não havia uma ênfase para insinuações genéricas de sensualidade. Em contraponto, justamente para fazer referência à esse desejo de corpo perfeito, esta campanha utiliza a imagem de uma mulher vestindo uma roupa totalmente transparente, que exibe não somente seus seios, mas todo seu corpo. Já a década de 2000, que ficou conhecida pelo surgimentos de novas tecnologias, e pelo uso de materiais sintéticos, está representada tanto no número 5 , que é composto por pixels, quanto na roupa da protagonista que é feita de plástico. O fundo preto faz referência à uma das principais cores da paleta Chanel, que para Gabrielle, serve para evidenciar o essencial e destacar o brilho da mulher.

Terceiridade: A protagonista é o ícone que representa uma mulher sedutora, mas também é um índice, que indica o contexto social da mulher da década de 90 . O № 5 que aparece três vezes, sendo duas delas nos frascos do próprio perfume e a terceira no " 5 " destacado ao fundo, são índices que indicam o objetivo da campanha. Além disso, o №5 (pixels) e o vestido plástico (material sintético) são índices que representam o ano 2000. O vestido também simboliza uma crítica à popularização da conquista pelo corpo perfeito, exaltando a cor bege, que para Chanel, significa naturalidade. E por fim, o fundo preto, cor característica da marca, simboliza a Chanel, em sua essência elegante e minimalista.

5 - A quinta campanha analisada foi a do ano de 2009 , protagonizada pela atriz Audrey Tautou famosa por protagonizar os filmes 0 famoso destino de Amélie Poulain (2000) e Coco antes de Chanel (2009):

Figura 8: Campanha de 2009

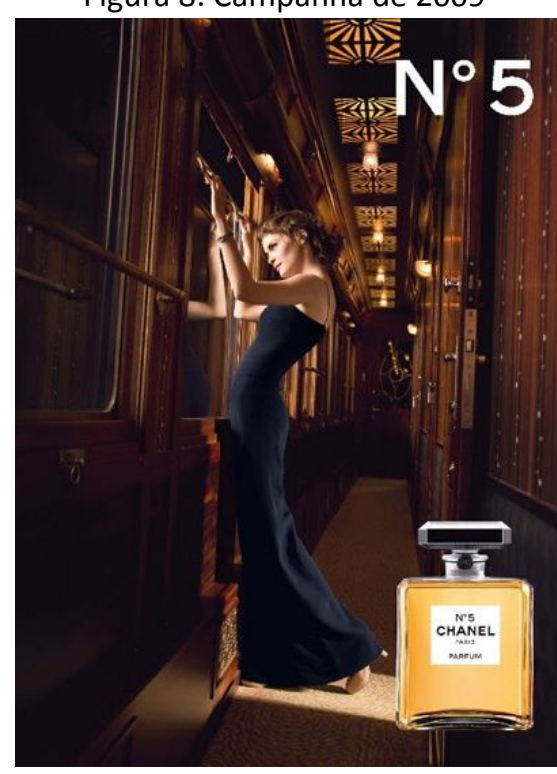

Fonte: chanel.com/pt_BR (2017)

Primeiridade: O cenário da campanha é um corredor de trem, nele a protagonista trajada em um vestido preto com os braços erguidos e mãos apoiadas na extremidade superior da janela, olhando para fora do trem, refletindo sua imagem no vidro da janela. Em destaque, na parte superior direita percebe-se o nome "№5" escrito, e na parte inferior direita o frasco do perfume.

Secundidade: A protagonista escolhida para a campanha, a atriz Audrey Tautou, ganhadora de alguns prêmios, costuma interpretar mulheres fortes e corajosas como a própria Gabrielle Chanel 
em Coco avant Chanel. ${ }^{2}$ As cores presentes em toda a composição da campanha apresentam tons sóbrios e as cores da paleta da marca. Como o vestido preto trajado pela protagonista; o frasco do perfume em amarelo outro (na parte inferior direita, como de costume); e a logomarca do perfume recebe na cor branca, contrastando com o restante da campanha.

Terceiridade: A protagonista representada é um ícone que referência a própria Gabrielle Chanel, com seu vestido preto que simboliza a paleta de cores da marca. As cores sóbrias do corredor, e os detalhes em dourado de todo o cenário, são índices da infância de Gabrielle, no orfanato cristão de Aubazine ${ }^{3}$ e simbolizam a elegância e também a paleta de cores da Chanel. O perfume representado num amarelo ouro sólido, é dessa vez um ícone, assim como a protagonista, e ambos representam a verdadeira essência da marca, Gabrielle, a criadora da marca e o №5, que é até hoje o maior sucesso da marca.

6 - A sexta campanha analisada foi a do ano de 2014, protagonizada pela supermodelo Gisele Bündchen, famosa por fazer parte do elenco do filme Táxi:

Figura 8: Campanha de 2014

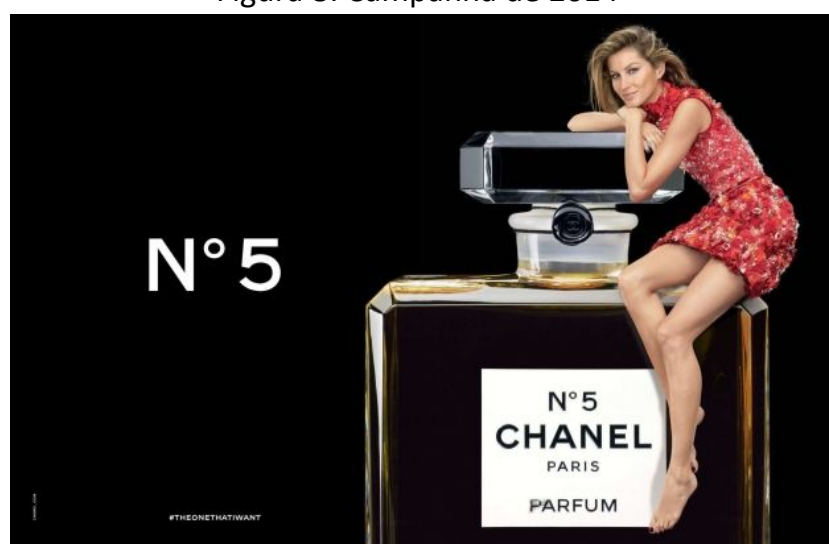

Fonte: chanel.com/pt_BR (2017)

Primeiridade: Com um fundo na cor preta, a campanha dá destaque ao frasco do perfume №5, que está representado num tamanho exagerado, ocupando a metade da campanha. Em cima do frasco, está a protagonista, usando um vestido vermelho, ela está sentada no lado direito do perfume com braços e queixo apoiados em cima da tampa do frasco, enquanto suas pernas pendendo ao lado do rótulo. E no lado esquerdo da campanha, bem ao lado do frasco, o nome "№5" flutuando escrito na mesma fonte e na cor branca.

Secundidade: A protagonista da campanha é a atriz e modelo Gisele Bündchen, considerada uma referência perene de beleza do século 21, que assim como Gabrielle Chanel, contradiz o estereótipo feminino de fragilidade. Um grande marco dessa quebra de estereótipo, foi a sua atuação no filme "Taxi", onde interpretou uma assaltante de banco. A campanha possui ao as cores da paleta da Chanel, que são preto, branco, bege, dourado e vermelho. Essa paleta tinha uma grande representatividade para Gabrielle Chanel, cada cor possuia um significado único e pessoal para ela. Nessa campanha todas essas cores estão presentes, o preto no fundo, o branco

\footnotetext{
2 Filme lançado em 2009, que conta a história de Gabrielle Chanel antes de criar a marca Chanel.

${ }^{3}$ Orfanato no qual Gabrielle Chanel foi criada e onde aprendeu costurar.

${ }^{4}$ Filme Lançado em 2004, onde Gisele Bündchen interpreta Vanessa que lidera o bando de assaltantes a banco Brasileiras.
} 
na escrita e no rótulo, o bege da pele exposta da protagonista, o dourado do próprio perfume e o vermelho do vestido. A típica simplicidade da composição, que dispensa informações em excesso, focando no essencial, o perfume.

Terceiridade: A protagonista da campanha, Gisele Bündchen é um ícone que representa a imagem de mulher que a marca Chanel sempre defendeu, com uma beleza natural e uma personalidade forte. É também um índice de tempo, que contextualiza o século 21 . O fundo preto que realça o essencial da campanha, simboliza o minimalismo e a elegância. O vermelho simboliza a jovialidade e o bom humor. O perfume, representado em maior tamanho que a protagonista, simboliza a perenidade da marca e do próprio perfume, comparando-a com Gisele Bündchen, que como dito antes, é considerada uma referência perene de beleza.

Com base nas análises realizadas acima é possível perceber a importância das campanhas publicitárias para a manutenção da marca Chanel, que apesar de não modificar a essência de seus produtos para se adequar à novos contextos, utiliza estas como meio de vincular sua imagem com os novos contextos sociais e manter-se em contato com seu público consumidor.

Para isso, o principal ícone utilizado em suas campanhas são as protagonistas, que por sua vez representam o papel social exercido por seu público alvo, tendo em vista que, como dito no capítulo "A importância da publicidade para a manutenção da marca" as mulheres buscam por meio das marcas, consumir a imagem daquilo que representa o que elas são, ou almejam ser.

Entretanto, essa imagem de auto-identificação pode se modificar juntamente com os novos contextos históricos. Por este motivo, a Chanel utiliza celebridades que estão em voga no momento da produção de cada campanha, para que estas sejam o indicativo de tempo que representa o novo contexto em que seu público está inserido. Por este motivo, utiliza em suas campanhas símbolos atualizados, que sejam facilmente identificados por seu público e que representem a permanente identidade da marca: que é caracterizada pela feminilidade, autoconfiança, liberdade, independência e sofisticação. Ou seja, nas campanhas, esse símbolo que de atemporalidade, que liga à marca ao consumidor, é a figura da mulher. Além disso, é importante ressaltar que, a marca também procura em todas as campanhas, quebrar algum paradigma social, para caracterizar uma mulher que foge aos padrões, assim como a própria Gabrielle.

Em suma, é possível perceber que a marca Chanel, para manter-se legítima, atualiza os signos em suas campanhas de acordo com as mudanças ocorridas no contexto social da mulher através das décadas. Para isso, utiliza principalmente a imagem de protagonistas famosas em determinadas décadas, e a partir da imagem delas agrega signos que representam o perfil da marca, do público e do contexto. Portanto, conclui-se que a marca Chanel permanece no mercado como uma marca de sucesso sem modificar sua essência ou a de seus produtos, através da forma que se comunica com seu público nas campanhas publicitárias, agregando índices e símbolos para evidenciar à imagem do seu verdadeiro ícone, índice e símbolo, a mulher Chanel.

\section{Referências}

BAGGIO, Adriana. Papéis sociais femininos na publicidade: contribuições da semiótica para sua identificação e categorização. Intexto, Porto Alegre, UFRGS, n. 37, p. 413-436, set/dez. 2016.

BELCHIOR, Camilo. Reciclando os sentidos. 1. ed. Belo Horizonte: Editora do autor, 2014. 
BONSIEPE, Gui; KELLNER, Petra; POESSNECKER, Holger. Metodologia experimental: desenho industrial. Brasília: CNPq/ Coordenação Editorial, 1984.

CARVALHAL, André. Moda com propósito: manifesto pela grande virada. 1.ed. São Paulo: Paralela, 2016.

CASTILHO, Kathia; VILLAÇA, Nízia; et al. O Novo Luxo. São Paulo: Anhembi Morumbi, 2006. p. 97-100, 212-213.

COSGRAVE, Bronwyn. Vogue on Coco Chanel. 1.ed. São Paulo: Globo, 2012. 160 p.

CHANEL. Inside Chanel: №5 propagandas. Disponível em: <http://inside.chanel.com/pt/gabrielle-pursuit-passion> acesso em 26/02/2018.

CHANEL. Inside Chanel: Marilyn e o №5. Disponível em: <http://inside.chanel.com/pt/marilyn> acesso em 26/02/2018.

FLICK, Uwe. Introdução à Pesquisa Qualitativa. 3.ed. Artmed Editora, 2009. p.26-30.

FORTY, Adrian. Objetos de desejo: design e sociedade desde 1750. Editora Cosac Naify, 2007.

KNOLL, Graziela Frainer. Discursos de gênero na publicidade: análise crítica de textos publicitários em revistas. Revista Sociais e Humanas, v. 25, n. 2, p. 239-252, 2012.

KRUCKEN, Lia. Design e Território-Valorização de identidades e produtos locais. São Paulo: Studio Nobel, 2009.

LIPOVETSKY, Gilles; ROUX, Elyette. O luxo eterno: da idade do sagrado ao tempo das marcas. São Paulo: Companhia das letras, 2005. 195 p.

MARCONI, Marina; LAKATOS, Eva Maria. Fundamentos de metodologia científica. 5. ed.-São Paulo: Atlas, 2003. p. 174-183

MAZZEO, J. Tilar. O segredo do Chanel №5. a história íntima do perfume mais famoso do mundo. Tradução de Talita Rodrigues. 5.ed. Rio de Janeiro: Rocco, 2011. p.7-12.

MIRANDA, Ana Paula. Consumo de moda: a relação pessoa-objeto. São Paulo: Estação das Letras e Cores, 2008.

NIEMEYER, Lucy. Elementos da semiótica aplicados ao Design. Rio de Janeiro: $2 A B$ série design, 2003.

NÖTH, Winfried. Panorama da Semiótica: de Platão a Pierce. 4.ed. São Paulo: Annablume, 2005. p.61-140.

PEIRCE, Charles Sanders. Semiótica e filosofia. São Paulo: Editora Cultrix, 1972.

RAMALHO, Sandra; OLIVEIRA. Imagem também se lê. Editora: Rosari, 2004. p.75-76.

SANTOS,G.F.C; L.C.D,NORA.Chanel N5. o luxo, a sedução e as estratégias de resistência cultural. disponível em : <http://anais-comunicon2015.espm.br/GTs/GT10/7_Goiamerico_Fellcio.pdf> acesso em 28/03/2018

SCÓZ, Murilo. VANDRESEN, Monique. RAMALHO, Sandra e OLIVEIRA. Proposições interativas modos de produzir sentidos. Santa Catarina: UDESC, 2016. $188 \mathrm{p}$.

REVISTA VILA CULTURAL. edição 139. São Paulo: novembro, 2015. Disponível em: <https://livrariadavila.com.br/wp-content/uploads/2017/10/VC139.pdf> acesso em 03/04/2018. 
